\title{
Early Childhood Education Teachers' Strategies Use in Order to Prevent Aggressive Behaviors in Classes: The Case of Turkey
}

\author{
Meral Taner Derman \\ Department of Basic Education, Education Faculty, Uludag University, Turkey
}

Copyright $(2017$ by authors, all rights reserved. Authors agree that this article remains permanently open access under the terms of the Creative Commons Attribution License 4.0 International License

\begin{abstract}
The aim of this research is to investigate the aggression types observed in class environment in preschool and primary schools and the strategies that teachers use in order to prevent aggressive behaviors in classes by variables like gender, seniority and socioeconomic level. 118 preschool teachers and 176 primary school teachers, a total of 294 teachers are involved in the research. A questionnaire prepared by the researcher was used in the study. Teachers stated that physical aggression is more common in preschool classes while verbal aggression is more common in primary school classes. In a comparison of schools' socioeconomic status, teachers working at schools with low, average and medium socioeconomic status stated that verbal aggression is the most common type of aggression in their classes. Upon examining strategies used as timely intervention means against aggression in classroom, it was determined that both preschool teachers in preschool education institutions and class teachers working at primary schools almost always use the methods such as "Encouraging mutual apology, reconciling, peacemaking", "Dialogue" and "Encouraging to place oneself in someone else's position", in other words empathizing. It can be said that teachers generally use positive conflict resolution methods in order to prevent aggression.
\end{abstract}

Keywords Aggression, Strategies, Preschool Teachers, Primary School Teachers, Prevent Aggressive Behaviors

\section{Introduction}

Offensive and disturbing behavior against other living beings or objects is defined as aggression [1], and it includes all behaviors that intend physical or psychological harm to others [2]. Aggression seen in childhood period indicates social, psychological, educational and behavioral problems in adulthood stage [3, 4]. Aggressive behavior in children is expected to continue until adulthood stage and can cause antisocial behaviors, low occupational status, alcohol use and crime [5], difficulties in communicating with peers, rejection by peers, academic failure, withdrawal from school and even dropout [6].

Children, who do not receive enough support for their social and emotional development during preschool period, tend to exhibit problem behaviors such as mocking their peers, quarrelling with them, bullying and aggression [7]. Behaviors such as swearing at someone (student, teacher, director) or physically hurting them, threatening with words, pushing someone to the ground in the hallway, fighting, bullying, mocking, nicknaming and vandalism can be good examples for aggressive behaviors at school [8].

Behavior tendencies of children, who exhibit high levels of aggressive behaviors at early childhood, tend to become part of their personality in time [9]. Behavior problems such as disagreement, disobedience, not sharing in early childhood can be transformed into serious behavior problems such as fighting, lying, stealing, interpersonal violence, crime and damage to someone else's property in childhood and adolescence [10].

Student behaviors, which consist of aggression and violence, are considered obstacles for educational efforts as well as being undesired behaviors [11]. In traditional practice, punishment of problem behavior is more often used to prevent inappropriate behavior. It is expected that if the teachers use classroom management methods such as repression, threatening, punishment, the aggressive behaviors of children are expected to increase even more [12]. Because, according to the Social Learning Theory, children can learn and reinforce many behaviors through modeling their teachers at school. However, in order for the daily training program to be carried out efficiently, the teacher needs to have effective classroom management skills and strategies to prevent undesired behaviors [13, 14]. Determining the strategies that early childhood education teachers use to deal with aggressive behavior in the class will 
help to increase the quality of early childhood education by using appropriate discipline methods in the classroom environment.

Studies conducted in recent years show that there is a similarity between $0-8$ years of age in physical, cognitive, language, social and emotional development. For this reason, experts agree that early childhood education should include 0-8 years of age rather than 0-6 years of age [15]. In Turkey, "Early Childhood Education" is a training period that covers the ages of $0-8$, from birth of the child to the third grade of the primary school. This education period targets the development of children in all areas, enhances the emotional development and perceiving skills, helps children in the process of reasoning and improves their creativity, ensures children's commitment to national, moral, ethical, cultural, human values, and allows self-expression, self-control and independence [16].

The aim of this research is to investigate the aggression types observed in class environment in preschool and primary schools and the strategies that teachers use in order to prevent aggressive behaviors in classes by variables like gender, seniority and socioeconomic level.

\section{Materials and Methods}

In the study, strategies to prevent aggressive behaviors of early childhood teachers in children were examined.

\subsection{Participants}

In Turkey, early childhood education periods cover $0-8$ ages. This age range refers to preschool period and the first three classes of primary school. So the preschool teachers and elementary school teachers were included because they were the teachers of this age group. 118 preschool teachers and 176 primary school teachers, a total of 294 teachers, 80 of whom are males and the rest are females, are involved in the research, which is a descriptive survey study.

\subsection{Data Collection Tools}

A questionnaire and teacher information form prepared by the researcher was used in the study. In the Teacher Information Form, information about the gender, branch, seniority and socioeconomic status of the early childhood teachers were included. In the introduction part of the Teacher Information Form, a section describing the researcher to the early childhood teachers and explaining the purpose of the research was given. Before starting, teachers were requested to participate in the study. The aim of the research was explained. It was specified that study is based on volunteering and their names will not be announced in no way.

\subsection{Analysis of Data}

Frequency/percentage and chi square test were used while analyzing the data. As a result of analyzes, preschool teachers stated that the aggression type that they observed the most in class environment was the physical aggression, while primary school teachers stated that it was verbal aggression.

\section{Findings}

In this section, the findings of strategies of early childhood education teachers to prevent aggressive behavior are included.

Table 1. Aggression types in classroom according to branch of teachers'

\begin{tabular}{|c|c|c|c|c|}
\hline & & \multicolumn{2}{|c|}{ Branch } & \multirow[b]{2}{*}{ Total } \\
\hline Aggression Type & & $\begin{array}{c}\text { Preschool } \\
\text { Teacher }\end{array}$ & $\begin{array}{l}\text { Class } \\
\text { Teacher }\end{array}$ & \\
\hline \multirow{2}{*}{ Physical Aggression } & $\mathrm{f}$ & 51 & 18 & 69 \\
\hline & $\%$ & 44 & 10,2 & 23,6 \\
\hline \multirow{2}{*}{ Verbal Aggression } & $\mathrm{f}$ & 42 & 92 & 134 \\
\hline & $\%$ & 36,2 & 52,3 & 45,9 \\
\hline \multirow{2}{*}{ Vandalism } & $\mathrm{f}$ & 6 & 4 & 10 \\
\hline & $\%$ & 5,2 & 2,3 & 3,4 \\
\hline \multirow{2}{*}{$\begin{array}{c}\text { Physical and Verbal } \\
\text { Aggression }\end{array}$} & $\mathrm{f}$ & 12 & 24 & 36 \\
\hline & $\%$ & 10,3 & 13,6 & 12,31 \\
\hline \multirow{2}{*}{$\begin{array}{c}\text { Physical Aggression and } \\
\text { Vandalism }\end{array}$} & $\mathrm{f}$ & 1 & 6 & 7 \\
\hline & $\%$ & 0,9 & 5,7 & 3,4 \\
\hline \multirow{2}{*}{$\begin{array}{c}\text { Verbal Aggression and } \\
\text { Vandalism }\end{array}$} & $\mathrm{f}$ & & 10 & 10 \\
\hline & $\%$ & & 5,7 & 3,4 \\
\hline \multirow{2}{*}{$\begin{array}{l}\text { Physical and Verbal } \\
\text { Aggression and } \\
\text { Vandalism }\end{array}$} & $\mathrm{f}$ & 4 & 18 & 22 \\
\hline & $\%$ & 3,4 & 10,2 & 7,5 \\
\hline
\end{tabular}

$\mathrm{X}^{2}=55,33 ; \mathrm{p}<0.05$

$44 \%$ of preschool teachers stated that physical aggression is more common while $52,3 \%$ of class teachers stated that verbal aggression is more common in their classrooms. It is seen that the difference between observations of teachers working in preschool education institutions and primary schools is quite significant. 
Table 2. Aggression types in classroom according to socioeconomic status

\begin{tabular}{|c|c|c|c|c|c|}
\hline \multirow[b]{2}{*}{ Aggression Type } & & \multicolumn{3}{|c|}{ Socioeconomic Status } & \multirow[b]{2}{*}{ Total } \\
\hline & & Low ses & Average ses & High ses & \\
\hline \multirow{2}{*}{ Physical Aggression } & $\mathrm{f}$ & 18 & 45 & 6 & 69 \\
\hline & $\%$ & 13,7 & 34,4 & 20 & 23,6 \\
\hline \multirow{2}{*}{ Verbal Aggression } & $\mathrm{f}$ & 62 & 60 & 12 & 134 \\
\hline & $\%$ & 47,3 & 45,8 & 40 & 45,9 \\
\hline \multirow{2}{*}{ Vandalism } & $\mathrm{f}$ & 6 & 4 & & 10 \\
\hline & $\%$ & 4,6 & 3,1 & & 3,4 \\
\hline \multirow{2}{*}{ Physical and Verbal Aggression } & $\mathrm{f}$ & 22 & 12 & 2 & 36 \\
\hline & $\%$ & 16,8 & 9,2 & 6,7 & 12,31 \\
\hline \multirow{2}{*}{$\begin{array}{l}\text { Physical Aggression and } \\
\text { Vandalism }\end{array}$} & $\mathrm{f}$ & 5 & 0 & 2 & 7 \\
\hline & $\%$ & 3,8 & & 6,7 & 3,4 \\
\hline \multirow{2}{*}{$\begin{array}{l}\text { Verbal Aggression and } \\
\text { Vandalism }\end{array}$} & $f$ & 2 & 6 & 2 & 10 \\
\hline & $\%$ & 1,5 & 4,6 & 6,7 & 3,4 \\
\hline \multirow{2}{*}{$\begin{array}{l}\text { Physical and Verbal Aggression } \\
\text { and Vandalism }\end{array}$} & $\mathrm{f}$ & 16 & 4 & 2 & 22 \\
\hline & $\%$ & 12,2 & 3,1 & 6,7 & 7,5 \\
\hline
\end{tabular}

$\mathrm{X}^{2}=69,03 ; \mathrm{p}<0.05$

According to a comparison of schools' socioeconomic status 47,3\% of teachers working at schools with low socioeconomic status, $45,8 \%$ of teachers working at schools with average socioeconomic status and $40 \%$ of teacher working at schools with high socioeconomic status stated that verbal aggression is the most common type in their classrooms. This difference between observations of teachers working at schools with varying socioeconomic statues can be considered statistically significant.

Table 3. Strategies used as timely intervention against aggressions observed in classroom by branch of teachers'

\begin{tabular}{|c|c|c|c|c|c|c|}
\hline \multirow{2}{*}{$\begin{array}{l}\text { Strategies used as timely intervention means whenever an aggressive behavior } \\
\text { is seen in classroom }\end{array}$} & \multicolumn{2}{|c|}{ Preschool Teacher } & \multicolumn{2}{|c|}{ Class Teacher } & \multicolumn{2}{|c|}{ Total } \\
\hline & $\mathrm{f}$ & $\%$ & $\mathrm{f}$ & $\%$ & $\mathrm{f}$ & $\%$ \\
\hline Dialogue & 73 & 61,86 & 141 & 80,11 & 214 & 72,79 \\
\hline Solution with an intervening third party & & & 6 & 3,409 & 6 & 2,041 \\
\hline Encouraging mutual apology, reconciling, peacemaking & 98 & 83,05 & 148 & 84,09 & 246 & 83,67 \\
\hline Encouraging to place oneself in someone else's position & 71 & 60,17 & 139 & 78,98 & 210 & 71,43 \\
\hline Prioritizing dialogue option and, if it fails, asking for his friends' help & 14 & 11,86 & 26 & 14,77 & 40 & 13,61 \\
\hline Prioritizing dialogue option and, if it fails, asking for another teacher's help & 12 & 10,17 & 28 & 15,91 & 40 & 13,61 \\
\hline Asking for support from Psychological Counseling and Guidance Specialist & 41 & 34,75 & 80 & 45,45 & 121 & 41,16 \\
\hline Letting school management handle the case & 6 & 5,085 & 30 & 17,05 & 36 & 12,24 \\
\hline Informing the family & 57 & 48,31 & 104 & 59,09 & 161 & 54,76 \\
\hline Threatening & 17 & 14,41 & 36 & 20,45 & 53 & 18,03 \\
\hline Leaving it to time & 4 & 3,39 & 12 & 6,818 & 16 & 5,442 \\
\hline Remaining silent, meeting halfway & 25 & 21,19 & 32 & 18,18 & 57 & 19,39 \\
\hline Sending him away to sit on the far corner of the classroom & 16 & 13,56 & 34 & 19,32 & 50 & 17,01 \\
\hline Showing no interest & & 0 & 2 & 1,136 & 2 & 0,68 \\
\hline
\end{tabular}

Upon examining strategies used as timely intervention means against aggression in classroom, it was determined that preschool teachers in preschool education institutions mostly use the options such as "Encouraging mutual apology, reconciliation, peacemaking" (83\%), "Dialogue" $(61,9 \%)$ and "Encouraging to place oneself in someone else's position", in other words empathizing $(60,2 \%)$.

As for classroom teachers working at primary schools, it was determined that they also use similar strategies, namely "Encouraging mutual apology, reconciliation, peacemaking" (84,1\%), "Dialogue" (80,1\%), and "Encouraging to place oneself to someone else's position", in other words empathizing (79\%). 
Table 4. Strategies used to prevent aggression observed in class by field

\begin{tabular}{|l|c|c|c|c|c|c|}
\hline \multirow{2}{*}{ Strategies Used To Prevent Aggression In General } & \multicolumn{2}{|c|}{ Preschool Teacher } & \multicolumn{2}{|c|}{ Classroom Teacher } & \multicolumn{2}{|c|}{ Total } \\
\cline { 2 - 7 } & $\mathrm{f}$ & $\mathbf{f}$ & $\mathrm{f}$ & $\mathrm{f}$ & $\mathbf{f}$ \\
\hline Giving conflict solving education & 8 & 6,78 & 38 & 21,59 & 46 & 15,65 \\
\hline Giving empathy education & 71 & $\mathbf{6 0 , 1 7}$ & 144 & $\mathbf{8 1 , 8 2}$ & 215 & $\mathbf{7 3 , 1 3}$ \\
\hline Analyzing the reasons of aggression & 75 & $\mathbf{6 3 , 5 6}$ & 94 & 53,41 & 169 & 57,48 \\
\hline Teaching how to identify and distinguish Emotions & 44 & 37,29 & 70 & 39,77 & 114 & 38,78 \\
\hline Learning about the attitudes of the family towards aggression & 57 & 48,31 & 74 & 42,05 & 131 & 44,56 \\
\hline Communicating with the family & 79 & $\mathbf{6 6 , 9 5}$ & 122 & $\mathbf{6 9 , 3 2}$ & 201 & $\mathbf{6 8 , 3 7}$ \\
\hline Teaching to accept differences and similarities & 33 & 27,97 & 84 & 47,73 & 117 & 39,8 \\
\hline Learning about friends and their characteristics & 16 & 13,56 & 36 & 20,45 & 52 & 17,69 \\
\hline Teaching the proper reactions towards negative emotions & 55 & 46,61 & 84 & 47,73 & 139 & 47,28 \\
\hline Teaching mutual respect & 67 & 56,78 & 114 & $\mathbf{6 4 , 7 7}$ & 181 & $\mathbf{6 1 , 5 6}$ \\
\hline Providing with problem solving skills & 43 & 36,44 & 86 & 48,86 & 129 & 43,88 \\
\hline Providing training for peacemaking & 18 & 15,25 & 36 & 20,45 & 54 & 18,37 \\
\hline Encouraging to participate in sports & 12 & 10,17 & 30 & 17,05 & 42 & 14,29 \\
\hline Encouraging to participate in social activities & 23 & 19,49 & 58 & 32,95 & 81 & 27,55 \\
\hline Reminding disciplinary rules of the school & 20 & 16,95 & 58 & 32,95 & 78 & 26,53 \\
\hline Preventing being labeled & 22 & 19,3 & 26 & 14,77 & 48 & 16,55 \\
\hline
\end{tabular}

Upon examining the strategies used to prevent aggression in general, it was determined that preschool teachers working in preschool institutions use "Communicating with families" (67\%), "Analyzing the reasons of aggression" (63,6\%), and "Giving empathy education" (60,2\%) strategies.

As for classroom teachers working in primary schools, it was determined that they use "Giving empathy education" $(81,8 \%)$, "Communicating with families $(69,3 \%)$ and "Teaching mutual respect" $(64,8 \%)$ strategies.

Table 5. Strategies used as timely intervention means whenever an aggressive behavior is seen in classroom by socioeconomic status

\begin{tabular}{|l|c|c|c|c|c|c|}
\hline \multirow{2}{*}{$\begin{array}{l}\text { Strategies used as timely intervention means whenever an aggressive } \\
\text { behavior is seen in classroom }\end{array}$} & \multicolumn{2}{|c|}{ Low ses } & \multicolumn{2}{c|}{ Medium ses } & \multicolumn{2}{c|}{ High ses } \\
\cline { 2 - 6 } & $\mathrm{f}$ & $\%$ & $\mathrm{f}$ & $\%$ & $\mathrm{f}$ & $\mathbf{7 3}$ \\
\hline Dialogue & 101 & $\mathbf{7 7 , 1}$ & 91 & $\mathbf{6 8 , 4 2}$ & 22 & $\mathbf{7 3 , 3 3}$ \\
\hline Solution with an intervening third party & 6 & 4,58 & 0 & 0 & 0 & 0 \\
\hline Encouraging mutual apology, reconciling, peacemaking & 117 & $\mathbf{8 9 , 3 1}$ & 109 & $\mathbf{8 1 , 9 5}$ & 20 & $\mathbf{6 6 , 6 7}$ \\
\hline Encouraging to place oneself in someone else's position & 103 & $\mathbf{7 8 , 6 3}$ & 89 & $\mathbf{6 6 , 9 2}$ & 18 & $\mathbf{6 0}$ \\
\hline Prioritizing dialogue option and, if it fails, asking for his friends' help & 22 & 16,79 & 16 & 12,03 & 2 & 6,667 \\
\hline $\begin{array}{l}\text { Prioritizing dialogue option and, if it fails, asking for another teacher's } \\
\text { help }\end{array}$ & 20 & 15,27 & 12 & 9,023 & 8 & 26,67 \\
\hline $\begin{array}{l}\text { Asking for support from Psychological Counseling and Guidance } \\
\text { Specialist }\end{array}$ & 54 & 41,22 & 53 & 39,85 & 14 & 46,67 \\
\hline Letting school management handle the case & 22 & 16,79 & 10 & 7,519 & 4 & 13,33 \\
\hline Informing the family & 70 & 53,44 & 75 & 56,39 & 16 & 53,33 \\
\hline Getting cross & 6 & 4,58 & & 0 & 2 & 6,667 \\
\hline Threatening & 24 & 18,32 & 25 & 18,8 & 4 & 13,33 \\
\hline Leaving it to time & 8 & 6,107 & 8 & 6,015 & 0 & 0 \\
\hline Remaining silent, meeting halfway & 41 & 31,3 & 16 & 12,03 & 0 & 0 \\
\hline Sending him away to sit on the far corner of the classroom & 28 & 21,37 & 18 & 13,53 & 4 & 13,33 \\
\hline Showing no interest & 0 & 0 & 0 & 0 & 2 & 6,667 \\
\hline
\end{tabular}


Upon examining the strategies used as timely intervention means whenever an aggressive behavior is seen in classroom by socioeconomic levels, it was determined that teachers working in schools with low socioeconomic statuses use "Encouraging mutual apology, reconciling, peacemaking" (89,3\%), "Encouraging to place oneself in someone else's position" -in other words, empathizing- $(78,6 \%)$ and "Dialogue" $(77 \%)$ the most. It was determined that teachers working in schools with medium socioeconomic statuses use "Encouraging mutual apology, reconciling, peacemaking" (82\%), "Dialogue" (68,4\%) and "Encouraging to place oneself in someone else's position" -in other words, empathizing- (66,9\%) strategies the most. As for teachers working in schools with high socioeconomic statuses, it was determined that they use "Dialogue" (73,3\%), "Encouraging mutual apology, reconciling, peacemaking" (66,7,3\%) and "Encouraging to place oneself in someone else's position" -in other words, empathizing- $(60 \%)$ strategies.

Table 6. Strategies used to prevent aggression observed in class by socioeconomic status

\begin{tabular}{|c|c|c|c|c|c|c|}
\hline \multirow{2}{*}{ Strategies Used To Prevent Aggression In General } & \multicolumn{2}{|c|}{ Low ses } & \multicolumn{2}{|c|}{ Medium ses } & \multicolumn{2}{|c|}{ High ses } \\
\hline & $\mathrm{f}$ & $\%$ & $\mathrm{f}$ & $\%$ & $\mathrm{f}$ & $\%$ \\
\hline Giving conflict solving education & 28 & 21,37 & 18 & 13,53 & 0 & 0 \\
\hline Giving empathy education & 98 & $\mathbf{7 4 , 8 1}$ & 99 & $\mathbf{7 4 , 4 4}$ & 18 & 60 \\
\hline Analyzing the reasons of aggression & 68 & 51,91 & 85 & 63,91 & 16 & 53,33 \\
\hline Teaching how to identify and distinguish Emotions & 54 & 41,22 & 52 & 39,1 & 8 & 26,67 \\
\hline Learning about the attitudes of the family towards aggression & 50 & 38,17 & 73 & 54,89 & 8 & 26,67 \\
\hline Communicating with the family & 92 & 70,23 & 91 & 68,42 & 18 & 60 \\
\hline Teaching to accept differences and similarities & 54 & 41,22 & 59 & 44,36 & 4 & 13,33 \\
\hline Learning about friends and their characteristics & 28 & 21,37 & 24 & 18,05 & 0 & 0 \\
\hline Teaching the proper reactions towards negative emotions & 64 & 48,85 & 65 & 48,87 & 10 & 33,33 \\
\hline Teaching mutual respect & 78 & $\mathbf{5 9 , 5 4}$ & 83 & 62,41 & 20 & 66,67 \\
\hline Providing with problem solving skills & 55 & 41,98 & 56 & 42,11 & 18 & 60 \\
\hline Providing training for peacemaking & 24 & 18,32 & 24 & 18,05 & 6 & 20 \\
\hline Encouraging to participate in sports & 14 & 10,69 & 22 & 16,54 & 6 & 20 \\
\hline Encouraging to participate in social activities & 40 & 30,53 & 37 & 27,82 & 4 & 13,33 \\
\hline Reminding disciplinary rules of the school & 37 & 28,24 & 33 & 24,81 & 8 & 26,67 \\
\hline Preventing being labeled & 22 & 16,79 & 20 & 15,04 & 6 & 20 \\
\hline
\end{tabular}

Upon examining the strategies used to prevent aggression in general by the socioeconomic status of the school, it was determined that preschool teachers working in schools with low socioeconomic statuses use "Giving empathy education" $(74,8 \%)$, "Communicating with families" $(70,2 \%)$ and "Teaching mutual respect" $(59,5 \%)$ strategies the most. It was determined that preschool teachers working in schools with medium socioeconomic statuses use "Giving empathy education" (74,4\%), "Communicating with families" $(68,4 \%)$ and "Analyzing the reasons of aggression" (63,9\%) strategies the most. As for teachers working in schools with high socioeconomic statuses, it was determined that they use "Teaching mutual respect" (66,7\%), "Giving empathy education" $(60 \%)$ and "Providing with problem solving skills" $(60 \%)$ strategies. 
Table 7. Strategies used as an immediate response to aggression observed in class by seniority of the teacher

\begin{tabular}{|c|c|c|c|c|c|c|c|c|c|}
\hline \multirow{3}{*}{$\begin{array}{l}\text { Strategies used as timely intervention means whenever an } \\
\text { aggressive behavior is seen in classroom }\end{array}$} & \multirow{3}{*}{ Field } & \multicolumn{8}{|c|}{ Seniority } \\
\hline & & \multicolumn{2}{|c|}{$\begin{array}{l}1-5 \text { years of } \\
\text { experience }\end{array}$} & \multicolumn{2}{|c|}{$\begin{array}{l}\text { 6-10 years of } \\
\text { experience }\end{array}$} & \multicolumn{2}{|c|}{$\begin{array}{c}11-19 \text { years of } \\
\text { experience }\end{array}$} & \multicolumn{2}{|c|}{$\begin{array}{c}20+\text { years of } \\
\text { experience }\end{array}$} \\
\hline & & $f$ & $\%$ & $\mathrm{f}$ & $\%$ & $f$ & $\%$ & f & $\%$ \\
\hline \multirow{2}{*}{ Dialogue } & PT & 56 & 64,37 & 10 & 41,67 & 7 & 100 & 0 & 0 \\
\hline & $\mathrm{CT}$ & 57 & 79,17 & 52 & 86,67 & 16 & 66,67 & 16 & 80 \\
\hline \multirow{2}{*}{ Solution with an intervening third party } & PT & 0 & 0 & 4 & 16,67 & 0 & 0 & 0 & 0 \\
\hline & $\mathrm{CT}$ & 2 & 2,78 & 0 & 0 & 0 & 0 & 0 & 0 \\
\hline \multirow{2}{*}{ Encouraging mutual apology, reconciling, peacemaking } & PT & 73 & 83,91 & 18 & 75 & 7 & 100 & 0 & 0 \\
\hline & $\mathrm{CT}$ & 64 & $\mathbf{8 8 , 8 9}$ & 50 & 83,33 & 18 & 75 & 16 & 80 \\
\hline \multirow{2}{*}{ Encouraging to place oneself in someone else's position } & PT & 48 & 55,17 & 18 & 75 & 5 & 71,43 & 0 & 0 \\
\hline & $\mathrm{CT}$ & 59 & 81,94 & 50 & 83,33 & 14 & 58,33 & 16 & 80 \\
\hline \multirow{2}{*}{$\begin{array}{l}\text { Prioritizing dialogue option and, if it fails, asking for his } \\
\text { friends' help }\end{array}$} & PT & 10 & 11,49 & 2 & 8,333 & 2 & 28,57 & 0 & 0 \\
\hline & $\mathrm{CT}$ & 8 & 11,11 & 12 & 20 & 2 & 8,33 & 4 & 20 \\
\hline \multirow{2}{*}{$\begin{array}{l}\text { Prioritizing dialogue option and, if it fails, asking for another } \\
\text { teacher's help }\end{array}$} & PT & 8 & 9,20 & 2 & 8,33 & 2 & 28,57 & 0 & 0 \\
\hline & $\mathrm{CT}$ & 12 & 16,67 & 8 & 13,33 & 2 & 8,33 & 6 & 30 \\
\hline \multirow{2}{*}{$\begin{array}{l}\text { Asking for support from Psychological Counseling and } \\
\text { Guidance Specialist }\end{array}$} & PT & 28 & 32,18 & 10 & 41,67 & 3 & 42,86 & 0 & 0 \\
\hline & $\mathrm{CT}$ & 24 & 33,33 & 32 & 53,33 & 12 & 50 & 12 & 60 \\
\hline \multirow{2}{*}{ Letting school management handle the case } & PT & 6 & 6,90 & 0 & 0 & 0 & 0 & 0 & 0 \\
\hline & $\mathrm{CT}$ & 16 & 22,22 & 12 & 20 & 0 & 0 & 2 & 10 \\
\hline \multirow{2}{*}{ Informing the family } & PT & 42 & 48,28 & 10 & 41,67 & 5 & 71,43 & 0 & 0 \\
\hline & $\mathrm{CT}$ & 30 & 41,67 & 46 & 76,67 & 12 & 50 & 16 & 80 \\
\hline \multirow{2}{*}{ Getting cross } & PT & 0 & 0 & 0 & 0 & 0 & 0 & 0 & 0 \\
\hline & $\mathrm{CT}$ & 4 & 5,56 & 2 & 3,33 & & & 2 & 10 \\
\hline \multirow{2}{*}{ Threatening } & PT & 12 & 13,79 & 2 & 8,33 & 3 & 42,86 & 0 & 0 \\
\hline & $\mathrm{CT}$ & 18 & 25 & 14 & 23,33 & 4 & 16,67 & 0 & 0 \\
\hline \multirow{2}{*}{ Leaving it to time } & PT & 4 & 4,6 & 0 & 0 & 0 & 0 & 0 & 0 \\
\hline & $\mathrm{CT}$ & 10 & 13,89 & 2 & 3,33 & 0 & 0 & 0 & 0 \\
\hline \multirow{2}{*}{ Remaining silent, meeting halfway } & PT & 21 & 24,14 & 4 & 16,67 & 0 & 0 & 0 & 0 \\
\hline & $\mathrm{CT}$ & 16 & 22,22 & 14 & 23,33 & 0 & 0 & 0 & 0 \\
\hline \multirow{2}{*}{ Sending him away to sit on the far corner of the classroom } & PT & 12 & 13,79 & 4 & 16,67 & 0 & 0 & 0 & 0 \\
\hline & $\mathrm{CT}$ & 20 & 27,78 & 14 & 23,33 & 0 & 0 & 0 & 0 \\
\hline \multirow{2}{*}{ Showing no interest } & PT & 0 & 0 & 0 & 0 & 0 & 0 & 0 & 0 \\
\hline & $\mathrm{CT}$ & 2 & 2,78 & 0 & 0 & 0 & 0 & 2 & 10 \\
\hline
\end{tabular}

\section{PT: Preschool Teacher}

CT: Classroom Teacher

Upon examining the strategies used as an immediate response to aggression observed in class by seniority of the teacher, it was determined that preschool teachers and classroom teachers with 1-5 years of experience use "Encouraging mutual apology, reconciling, peacemaking" strategy the most and also that preschool teachers with 6-10 and 11-19 years of experience use "Encouraging mutual apology, reconciling, peacemaking" strategy the most.

As for classroom teachers with 6-10, 11-19 and 20+ years of experience, it was determined that they use "Dialogue" strategy. 
Table 8. Strategies aimed at preventing aggression observed in class by seniority

\begin{tabular}{|c|c|c|c|c|c|c|c|c|c|}
\hline \multirow{3}{*}{ Strategies Used To Prevent Aggression In General } & \multirow{3}{*}{ Field } & \multicolumn{8}{|c|}{ Seniority } \\
\hline & & \multicolumn{2}{|c|}{$\begin{array}{c}\text { Teachers with 1-5 } \\
\text { years of experience }\end{array}$} & \multicolumn{2}{|c|}{$\begin{array}{l}\text { Teachers with 6-10 } \\
\text { years of experience }\end{array}$} & \multicolumn{2}{|c|}{$\begin{array}{l}\text { Teachers with 11-19 } \\
\text { years of experience }\end{array}$} & \multicolumn{2}{|c|}{$\begin{array}{l}\text { Teachers with } 20+ \\
\text { years of experience }\end{array}$} \\
\hline & & $\mathrm{f}$ & $\%$ & $\mathrm{f}$ & $\%$ & f & $\%$ & f & $\%$ \\
\hline \multirow{2}{*}{ Giving conflict solving education } & PT & 8 & 9,20 & 0 & 0 & 0 & 0 & 0 & 0 \\
\hline & $\mathrm{CT}$ & 22 & 30,56 & 10 & 16,67 & 2 & 8,33 & 4 & 20 \\
\hline \multirow{2}{*}{ Giving empathy education } & PT & 48 & 55,17 & 18 & 75 & 5 & 0 & 0 & 0 \\
\hline & $\mathrm{CT}$ & 54 & 75 & 50 & 83,33 & 22 & 0 & 18 & 0 \\
\hline \multirow{2}{*}{ Analyzing the reasons of aggression } & PT & 62 & 71,26 & 10 & 41,67 & 3 & 42,86 & 0 & 0 \\
\hline & $\mathrm{CT}$ & 38 & 52,78 & 28 & 46,67 & 12 & 50 & 16 & 80 \\
\hline \multirow{2}{*}{ Teaching how to identify and distinguish emotions } & PT & 36 & 41,38 & 8 & 33,33 & 0 & 0 & 0 & 0 \\
\hline & $\mathrm{CT}$ & 34 & 47,22 & 22 & 36,67 & 6 & 25 & 8 & 40 \\
\hline \multirow{2}{*}{$\begin{array}{l}\text { Learning about the attitudes of the family towards } \\
\text { aggression }\end{array}$} & PT & 46 & 52,87 & 6 & 25 & 5 & 71,43 & 0 & 0 \\
\hline & $\mathrm{CT}$ & 28 & 38,89 & 30 & 50 & 6 & 25 & 10 & 50 \\
\hline \multirow{2}{*}{ Communicating with the family } & PT & 58 & 66,67 & 14 & 58,33 & 7 & 100 & 0 & 0 \\
\hline & $\mathrm{CT}$ & 44 & 61,11 & 44 & 73,33 & 16 & 66,67 & 18 & 90 \\
\hline \multirow{2}{*}{ Teaching to accept differences and similarities } & PT & 26 & 29,89 & 4 & 16,67 & 3 & 42,86 & 0 & 0 \\
\hline & $\mathrm{CT}$ & 40 & 55,56 & 24 & 40 & 8 & 33,33 & 12 & 60 \\
\hline \multirow{2}{*}{ Learning about friends and their characteristics } & PT & 14 & 16,09 & 2 & 8,33 & 0 & 0 & 0 & 0 \\
\hline & $\mathrm{CT}$ & 20 & 27,78 & 12 & 20 & 0 & 0 & 4 & 20 \\
\hline \multirow{2}{*}{$\begin{array}{l}\text { Teaching the proper reactions towards negative } \\
\text { emotions }\end{array}$} & PT & 38 & 43,68 & 10 & 41,67 & 7 & 100 & 0 & 0 \\
\hline & $\mathrm{CT}$ & 36 & 50 & 32 & 53,33 & 6 & 25 & 10 & 50 \\
\hline \multirow{2}{*}{ Teaching mutual respect } & PT & 50 & 57,47 & 10 & 41,67 & 7 & 0 & 0 & 0 \\
\hline & $\mathrm{CT}$ & 50 & 69,44 & 36 & 60 & 10 & 0 & 18 & 90 \\
\hline \multirow{2}{*}{ Providing with problem solving skills } & PT & 33 & 37,93 & 6 & 25 & 4 & 57,14 & & \\
\hline & $\mathrm{CT}$ & 46 & 63,89 & 24 & 40 & 8 & 33,33 & 8 & 40 \\
\hline \multirow{2}{*}{ Providing training for peacemaking } & PT & 10 & 11,49 & 8 & 33,33 & 0 & 0 & 0 & 0 \\
\hline & $\mathrm{CT}$ & 16 & 22,22 & 12 & 20 & 8 & 0 & 0 & 0 \\
\hline \multirow{2}{*}{ Encouraging to participate in sports } & PT & 8 & 9,195 & 4 & 16,67 & 0 & 0 & 0 & 0 \\
\hline & $\mathrm{CT}$ & 4 & 5,556 & 10 & 16,67 & 6 & 25 & 10 & 50 \\
\hline \multirow{2}{*}{ Encouraging to participate in social activities } & PT & 12 & 13,79 & 6 & 25 & 5 & 0 & 0 & 0 \\
\hline & $\mathrm{CT}$ & 20 & 27,78 & 26 & 43,33 & 8 & 0 & 4 & 20 \\
\hline \multirow{2}{*}{ Reminding disciplinary rules of the school } & PT & 15 & 17,24 & 2 & 8,33 & 3 & 0 & 0 & 0 \\
\hline & $\mathrm{CT}$ & 16 & 22,22 & 24 & 40 & 10 & 0 & 8 & 40 \\
\hline \multirow{2}{*}{ Preventing being labeled } & $\mathrm{PT}$ & 16 & 18,39 & 2 & 8,33 & 4 & 57,14 & 0 & 0 \\
\hline & $\mathrm{CT}$ & 10 & 13,89 & 12 & 20 & 2 & 8,33 & 2 & 10 \\
\hline
\end{tabular}

PT: Preschool Teacher

CT: Classroom Teacher 
Upon examining the strategies used to prevent to aggression observed in class by seniority of the teacher, it was determined that preschool teachers with 1-5 years of experience use "Analyzing the reasons of aggression" strategy the most and that preschool teachers and classroom teachers with 6-10 years of experience use "Giving empathy education" strategy the most. It was determined that preschool teachers with 11-19 years of experience use "Learning about the attitudes of the family towards aggression" strategy the most.

As for classroom teachers with 1-5, 11-19 and 20+ years of experience, it was determined that they use "Communicating with the family" strategy.

\section{Conclusions}

In this section, the findings are discussed and interpreted in the light of the sub-objectives of the research.

Teachers stated that physical aggression is more common in preschool classes while verbal aggression is more common in primary school classes. Gültekin Akduman [17] states that in addition to physical aggression, relational and verbal peer bullying can also be observed in preschool period. Ostrov et al. [18] reported in their study conducted on three year old children that children exhibit complex relational aggression behaviors such as gossiping and revealing their friends' secrets to others.

Türnüklü and Yıldız [19] determined that the most common problem behaviors in classroom are swearing, physical assault by peers, stealing, teasing by peers, lying to teacher, inflicting damage to school properties and others' properties.

In a comparison of schools' socioeconomic status, teachers working at schools with low, average and medium socioeconomic status stated that verbal aggression is the most common type of aggression in their classes.

Upon examining strategies used as timely intervention means against aggression in classroom, it was determined that both preschool teachers in preschool education institutions and class teachers working at primary schools almost always use the methods such as "Encouraging mutual apology, reconciling, peacemaking", "Dialogue" and "Encouraging to place oneself in someone else's position", in other words empathizing. In a study conducted by Zindi [20], students were asked "What do the teachers do to stop bullying?" and $41 \%$ of students stated that teachers "never take action, $33 \%$ of students stated that they "sometimes do something" and only $18 \%$ of students stated that their teachers "almost always try to stop bullying". On the other hand, when teachers were asked the same question, they used the response "almost always try to stop bullying" three times more than students.

Türnüklü and İlleez [21] analyzed the strategies used by teachers to resolve disputes among students and determined that "talking, sharing their own experiences and giving advises" is one of the most preferred strategies that is used to resolve disputes. The Same study also establishes that administrator, compared to teachers conflict with students, are more inclined to use administrative means instead of trying to deal with the problem.

Punishment in early childhood, which constitutes an important period of children's personality development, can disrupt children's mental health [22].

When strategies used to prevent aggression observed in class were analyzed in general, it was determined that preschool teachers, who work at preschool education institutions, use strategies such as "Contacting the family", "Analyzing causes of aggression" and "Giving empathy education" while class teachers mostly use "Giving empathy education", "Contacting the family" and "Teaching mutual respect". It is known that having communication skills and being empathetic are very important in controlling and preventing aggression [23,24]. Yavuzer, Gündoğdu and Dikici [25] examined the opinions of teachers working in primary schools and high schools on the reasons of violence in school environment and the ways to prevent them. These teachers suggested more effective guidance services and adhering to school disciplinary rules as precautions against aggression. In the other paper, the coping strategies of the preschool teachers with the aggressive behaviour patterns have been seen to be verbal warning, $2^{\text {nd }}$ type punishment, ignoring, suggesting solutions, cognitive persuasion, changing the place of the child/giving a break, 1st type punishment, providing guidance, understanding the problem, getting help and empathy [26].

When strategies, which are used as timely intervention against aggressive behaviors in classroom, were analyzed by socioeconomic status of schools, it was determined that teachers working at schools with low, average and high socioeconomic statues almost always use "Encouraging mutual apology, reconciling, peacemaking", "Encouraging to place oneself in someone else's position", namely empathizing, and "Dialogue" strategies. When strategies used to prevent aggression were analyzed according to socioeconomic level of schools, where teachers work, it was discovered that both in low and average socioeconomic level schools, strategies such as "Giving empathy education", "Contacting the family" and "Teaching mutual respect" and "Analyzing causes of aggression" are practiced while teachers in high socioeconomic level schools prefer strategies like "Teaching mutual respect", "Giving empathy education", "Contacting the family" and "Teaching problem solving skills". It can be said that teachers generally use positive conflict resolution methods in order to prevent aggression.

Teachers' methods for class management can vary as their professional experience changes. In a study, where Dinçer and Akgün [27] analyzed the relation between class management skills and various factors to find out whether professional experience is a determining factor for occurrences of aggressive behaviors in classroom, they determined that teachers with 6 years of teaching experience have better class management skills compared to teachers 
with 5 years of teaching experience. In another study, where Denizel Güven and Cevher [28] determined preschool teachers' class management skills and analyzed their relation with various factors, it was discovered that even though the average of class management skills increases in parallel with the increase in years of professional life, there are no significant difference between groups. In his study to determine problem behaviors in preschool classes and the methods used by teachers use to deal with such behaviors Sadık [29] determined that teachers' methods vary depending on their experiences. On the other hand, in their study to determine teacher attributes in terms of class management Yeşilyurt and Çankaya [30] found out a significant difference in their class management attributes according to professional experience factor.

\section{Recommendations}

Before anything else teachers should set an example for their students. In-service training about education programs and new strategies for preventing aggression should be given to teachers. Teachers should be provided with in-service trainings about empathy education and conflict resolution education.

\section{REFERENCES}

[1] P. Boxer and M. S. Tisak. Children's beliefs about the continuity of aggression, Aggressive Behavior, Vol. 31, No.2, 172-188, 2005.

[2] E. Aytekin. Elementary school students' aggression level and acceptance/rejection perception to parents and its analysis by demographic variables, Master Thesis, Gazi University Graduate School of Educational Sciences, 2015.

[3] D. Scwartz, A. H. Gorman, J. Nakamoto and T. McKay. Popularity, social acceptance, and aggression in adolescent peer groups: Links with academic performance and school attendance, Developmental Psychology, Vol. 42, No. 6, 11161127, 2006.

[4] N. R. Crick, J. M. Ostrov and N. E. Werner. A longitudinal study of relational aggression, physical aggression, and children's social-psychological adjustment, Journal of Abnormal Child Psychology, Vol. 34, No. 2, 131-142, 2006.

[5] L. Keltikangas-Järvinen. Aggressive behavior and social problem-solving strategies: A review of the findings of a seven-year follow-up from childhood to late adolescence, Criminal Behaviour and Mental Health, Vol. 11, No. 49, 236250, 2001.

[6] G. S. Tekinsav-Sütçü. Investigating the effect of the cognitive-behavioral group intervention to reducing anger and aggression for adolescents. Unpublishing Doctoral Thesis, Ege University, Social Sciences Institutes, İzmir, 2006.

[7] S. Özbey, and F. Alisinanoğlu. A Study on Problem Behavior of 60-72 Months Children Who Attending Public Early
Childhood Education Institution, The Journal of International Social Research, Vol. 2, No. 6, 493-517, 2009.

[8] T. G. Moeller. Youth aggression and violence: A psychological approach, Lawrence Erlbaum Associates London, 2001.

[9] R. V. Kail. Children and their development (5th ed.), Pearson Education Inc., New Jersey, 2010.

[10] F. Lösel and D. Bender. Child social skills training in the prevention of antisocial development and crime. In (Ed.) D. P. Farrington \& B. C. Welsh, "The Oxford Handbook Of Crime Prevention" (102-129). Oxford, UK: Oxford University Press, 2012.

[11] Y. Yavuzer. Violence and aggression in schools: Risk factors related to teachers and schools and prevention strategies, Natioanl Education, Vol. 192, 43-61, 2011.

[12] B. Şevkin. Searching the effects of conflict resolution styles and agression tendency on 4th and 5th grade students in primary school of 'negotiation (problem solving) and mediation' education programme, Unpublishing Master Thesis, Dokuz Eylül University Educational Sciences Institutes, İzmir, 2008.

[13] D. Erbaş and Ş. Yücesoy Özkan. Positive behavioral support practices in reducing problem behaviors: Family and teacher handbook. Ankara: Maya Academy Publishing, 2010.

[14] H. Uysal, S. Akbaba Altun and E. Akgün. The strategies preschool teachers use when confronted with children's undesired behaviors. Elementary Education Online, Vol. 9, No. 3, 971-979, 2010.

[15] M. Z. Ilgar and S. Coşgun Ilgar. An overview of early childhood education in Turkey. İstanbul Sabahattin Zaim University Journal of Social Sciences, Vol. 1, No. 2, 219-228, 2013.

[16] N. Y1lmaz, (1999). Kindergarten Teacher's Guide Book, İstanbul: Ya-Pa Publishing

[17] G. Gültekin Akduman. An Investigation of Peer Bullying at Preschool Period. Community and Social Work, Vol. 23, No. 1, 121-138, 2012.

[18] J. M. Ostrov, K. E. Woods, E. A. Jansen, J. F. Casas, \& N. R. Crick. An observational study of delivered and received aggression, gender, and social psychological adjustment in preschool: "This white crayon doesn't work...", Early Childhood Research Quarterly, Vol. 19, No. 2, 355-371, 2004.

[19] A. Türnüklü, and V. Yıldız. Strategies for teachers to deal with unwanted behaviors of students-II-. The Journal of Contemporary Education, Vol. 285, 32-36, 2002.

[20] F. Zindi. Bullying at boarding school: A Zimbabwe study. Research in Education, Vol. 51, 23-32, 1994.

[21] A. Türnüklü, and M. İlleez. Examination of teachers' conflict resolution strategies and tactics from the perspective of social constructivism. Eurasian Journal of Educational Research, Vol. 6, no. 22, 221-232, 2006.

[22] R. Karaca and F. E. İkiz. A Contemporary Approach to Guidance and Psychological Counseling, Ankara: Nobel Publishing, 2014. 
[23] F. Korkut. School based preventive guidance and psychological counseling, An1 Publishing, Ankara, 2004.

[24] M. Taner Derman. The impact of Empathy Education Programme which was performed on 10-11 year old children from different socioeconomic levels on the aggression level, Unpublishing Doctoral Thesis, Uludag University, Educational Sciences Institutes, Bursa, 2011.

[25] Y. Yavuzer, R. Gündoğdu, and A. Dikici. Teachers' perceptions about school violence in one Turkish city. Journal of School Violence, Vol. 8, No. 1, 29-41, 2009.

[26] S. Öngören Özdemir and K. Tepeli. Examining the strategies of preschool teachers to cope with aggressive behaviors. Journal of Ahi Evran University Kurşehir Education Faculty (KEFAD) Vol. 17, No. 2, 51-70, 2016.
[27] Ç. Dinçer, and E. Akgün. Study of validity and reliability of pre-school teachers' evaluation of classroom management scale, 19. Congress of National Educational Sciences, Nicosia, Turkish Republic of Northern Cyprus, 16-18 September, 2010.

[28] E. Denizel Güven and F. N. Cevher. The level of preschool teachers' classroom management skills and its relations with different variables, Journal of Pamukkale University Education Faculty, Vol. 2, No. 18, 1-22, 2005.

[29] F. Sadık. Behavior problems observed in pre-school classes and methods used by the teachers to take care of these behaviors, Eurasian Journal of Educational Research, Vol. 13, 88-97, 2004.

[30] E. Yeşilyurt, and İ. Çankaya. Determining teachers' qualities in the aspect of classroom management. Electronic Journal of Social Sciences, Vol. 7, No. 23, 274-295, 2008. 